Vol. 11 (2): 327-330 (2021)

\title{
FOOD POVERTY, HUNGER AND ECONOMY
}

\author{
Tahseen Fatima Miano ${ }^{12 *}$ \\ $1 *$ Erciyes University, Faculty of Food Engineering, Department of Food Engineering, Kayseri 38039, Turkey; \\ ${ }^{2 *}$ Sindh Agriculture University, Institute of Food Sciences and Technology, Tandojam 70060, Pakistan; \\ *Corresponding Author Tahseen Fatima Miano, e-mail: tahseenfm@yahoo.com;
}

Received February 2021; Accepted March 2021; Published April 2021;

DOI: https://doi.org/10.31407/ijees11.218

\begin{abstract}
This study is focused on the interrelation of food poverty, hunger and economic values which has progressed with the economic and social policies that have the connection with the sustainable food production, marketing import and export policies of agricultural food commodities owing there values in rural and urban areas. Most of the $63 \%$ world population is facing hunger and economic problems they can be minimized through sustainable macroeconomic growth and stability to alleviate poverty, policies to provide resources throughout the world costeffective benefit food programs, providing basic necessities of physical and social shelters for individual life. Development of Entrepreneurship among the peoples through private and government sector with fiscal and monetary flexible work practices policies were applying new technologies creating new innovative ideas focusing on competitive business strategies ideas to cross the barriers with innovation motivation and cooperation will lead the sustainable availability of food; reduce hunger with increasing economy through the world.
\end{abstract}

Keywords: Food, Hunger, Economy, Innovation, policies. 